\title{
Do precedents create rules?
}

\author{
GRANT LAMOND *
}

The doctrine of precedent is one of the most distinctive features of the modern common law. Understanding the operation of precedent is important for our theorising about the nature of law, since any adequate theory must be compatible with the practice. In this paper I will explore the conventional view of precedent, endorsed by practitioners and many legal philosophers alike. I will argue that, for all its attractions, it provides a distorted view of the nature of precedent. The distortion grows out of the basic assumption that precedents create rules, and thus that the common law can be understood as a form of rule-based decision-making. Instead, the common law is a form of case-by-case decision-making, and the doctrine of precedent constrains this decision-making by requiring later courts to treat earlier cases as correctly decided. The relevance of earlier cases is not well understood in terms of rulesthey are better understood as a special type of reason. This is not simply a technical debate about the proper way to capture the way precedent operates in legal reasoning: how we characterise precedent matters to our understanding of the function of precedent in the common law. The rule-based model suggests that the function of precedent is to settle the law so that it can guide individuals and the courts. The reason-based model suggests that the function is to compensate for the erosion of consensus in the common law by simultaneously fixing starting points for decisionmaking without giving the judiciary law-making power.

I will represent the conventional view of precedent in terms of four propositions. My claim is not that every practitioner or

^ Balliol College, Oxford. The initial research for this paper was carried out while visiting at the Faculty of Law and the School of Philosophy at the University of Sydney. I would like to thank John Finnis and Larry Alexander for their very helpful commentaries on two separate occasions- the Oxford Jurisprudence Colloquium (Finnis) and the Analytical Legal Philosophy Conference in New York (Alexander). I would also like to thank the participants at those gatherings for their comments, especially Joseph Raz and John Gardner. I am particularly grateful to John Stanton-Ife for helping me to clarify my thinking on this topic.

(C) Grant Lamond 2005 
theorist would endorse every detail of these propositions, but that they capture fairly well a widely held view. These are only very rough characterisations, which different theorists would expand upon in different ways, but they are sufficient as a starting point for discussion. The four propositions are these:

(1) Precedents lay down rules in their rationes, and such rules are binding in later cases whose facts fall within the scope of those rules.

(2) Some later courts have the power to overrule precedents, but all later courts have the power to distinguish precedents, which amounts to a limited power to modify the rule laid down in the precedent case.

(3) The application of the rule in later cases is determined by the precedent court's justification(s) for the rule.

(4) The function of the doctrine of precedent is to create new legal rules to settle uncertainty in the law, so as to provide guidance to individuals and the courts.

On the conventional view, then, what is binding in a precedent is the ratio, and the ratio is a rule that can be applied in later situations to guide individuals and future courts. The practice of distinguishing, whereby later courts are entitled to avoid the application of the precedent although the facts fall within the scope of the ratio, is thus a power to modify the ratio- a power subject to strict limits. The application of the rule laid down in the precedent's ratio is to be determined by reference to the justification given by the court for its holding-it must be interpreted in accordance with the intentions of the maker of the rule. All in all, then, precedents give rise to a form of rule-based decision-making which differs from other forms in two minor ways: (i) the ratio has to be constructed from the judgment in a case, and is not based upon a canonical formulation by the court; and (ii) later courts have a limited power to modify the ratio that applies to the case before it.

The conventional view of precedent is not without its philosophical critics. They argue that the fact that the ratio of a precedent is not based upon a canonical formulation given by the 
court, but must be constructed from the judgment as a whole, provides a basis for denying that the ratio constitutes the binding part of a precedent at all. Instead of there being a binding legal rule, it is argued, later courts are bound by the principles which justify the result reached in the earlier case. On one approach later courts are bound by the principles the precedent court itself used to justify the result $^{1}$; on another approach later courts are bound by whatever principles provide the best justification for the outcomes reached in the body of cases to which the precedent belongs. ${ }^{2}$ Although I agree with these critics that precedents do not lay down rules, my argument does not proceed on the basis that rationes play no independent role in legal reasoning.

Instead, what is distinctive about the reason-based view I am proposing is that it regards a precedent as a decision relative to a particular factual context. The ratio points to those features of the case which provide sufficient reason(s) for the result, given that context. Unlike a rule, it does not attempt to pre-empt what should be done in similar cases where the facts differ-that has to be decided on the balance of reasons present in the latter case. This is why the basic obligation under the doctrine of precedent is either to follow or distinguish the earlier decision ${ }^{3}$ - a disjunctive obligation. Distinguishing and following are simply two sides of the same coin: case-by-case decision-making is the process of determining whether or not a precedent should be followed given the differences between the case before the court and the precedent case. Furthermore, in deciding whether to follow or distinguish, the later court is not asking what the precedent court would have decided: it is making its own assessment of the merits of the situation. Later courts, then, are not bound by rationes-they are bound by precedents; and they are not bound to follow precedents-they are bound to determine whether they should be followed or distinguished.

The starting point for a reason-based account then is a reflection upon what is, in truth, the fundamental requirement of the common law doctrine of precedent, vi\%: that later courts treat earlier cases as correctly decided on their facts. What flows from

1 Perry 1987.

2 Dworkin 1978, 110-118; Moore 1987.

${ }^{3}$ Raz 1979, 185; Eisenberg 1988, 61-2. 
this requirement is the necessity of reaching a decision in a later case which is consistent with the correctness of the earlier decision. The question is what sort of 'consistency' does this entail? The conventional view interprets consistency in terms of the use of the same 'rule' as that relied upon in the precedent case. Those who demur on the significance of rationes interpret it as entailing the application of the same set of principles which justified the preceding case(s). The reason-based view requires that later courts accept the correctness of the precedent court's assessment of the balance of reasons on the facts of the precedent case.

Why prefer an account of precedent in terms of reasons rather than rules? Essentially because there are a range of features of common law reasoning which are more intelligible from this perspective, most notably the existence of the practice of distinguishing. But such an account also casts light on the following features: the lack a fixed, canonical formulation for rationes; the significance of the facts of the case and the detailed attention that is often given to them in common law adjudication; the persistence of theoretical disagreement on the significance of the precedent court's justification for its ratio; and the question of how the modern doctrine of precedent fits into the history of the common law.

This paper is divided into three sections. In the first I examine the rule-based account in greater depth in order to demonstrate the difficulty of reconciling it with the practice of distinguishing. Although this is the fundamental stumbling block for the account, I also note a number of other features of the common law which sit uneasily with the idea that precedents lay down rules. In the second section I develop the account of precedent as case-by-case decisionmaking, explaining its similarities and dissimilarities to rule-based decision-making. I highlight various features of the common law which make case-by-case decision-making appear closer to rulebased decision-making than it really is. Finally, in the third section I turn to the function of the doctrine of precedent, and what can be learnt from the fact that precedents do not lay down rules.

Before proceeding, a few points are needed to delimit the scope of the paper. The first is that the focus of the paper is on those areas of the law primarily governed by the common law rather than statute. Although some points are raised on the nature of statutory 
interpretation, my interest is in the operation of the doctrine of precedent in the common law. Various adjustments would need to be made to extend the analysis to the role of precedent in statutory interpretation. The second clarification is that my focus will be on the uncomplicated situation in which a court delivers a single judgment providing a single ground for the result. I am not concerned with the complications which arise in legal practice from cases where there is no agreed majority judgment in favour of the result, or the judgment gives two separate but individually sufficient grounds for the result, or no reasons at all are given by the court. These questions are important for practitioners, but the key theoretical questions arise from the uncomplicated single judgment case. Finally, the aim of the paper is to provide a better understanding of the nature of precedent in the common law, rather than to discuss the possible relevance of this understanding for the debate about the fundamental basis of law. Despite the great interest of that debate, there is no simple or straightforward implication of the case-by-case analysis of precedent for theoretical claims such as the sources thesis or interpretivist accounts of law.

One final preliminary. For the sake of expository convenience, I have tried to use the following terms in a consistent manner in this paper. When I speak of a 'case', I mean a legal dispute which has or could be brought before a court. The 'result' of the case refers to the legal result of the case for those parties if brought before a court, vi\%: who won or lost, and what legal consequences flowed for the parties from that outcome. By ratio I mean what most (but by no means all) lawyers mean when they speak of the ratio of a court judgment, vir the proposition of law which the decision authoritatively creates. The 'justification' for the ratio comprises all of those reasons given by the court in support of that proposition of law-it is the rationale for the ratio. And the court's 'decision' refers to all three aspects of the court's judgment: (a) the justification for (b) the proposition of law which contributes to (c) the result in the case. I use the term 'precedent court' and 'precedent case' to refer to the earlier court and dispute; and I speak of 'later courts' and 'later cases' to refer to those courts and disputes which are bound by the precedent. 


\section{The conventional view of precedent}

The conventional view of precedent, I have claimed, is based on the idea that it is a form of 'rule-based' decision-making. One possible concern with the contrast I have drawn between 'rule-based' and 'reason-based' decision-making is that the distinction may collapse, leaving the 'special type of reason' as a kind of rule, or the conventional account of rules as simply a particular type of reason-or both. ${ }^{4}$ After all, when practitioners speak of 'rules' they rarely have in mind a tight conception of one specific kind of normative standard. They may just as well be referring to the type of case-by-case decision-making which I have contrasted with the use of rules. Indeed I take it that this is the case, i.e. that although practitioners use the language of 'rules' to describe their practices, they simply mean that precedent involves the use of the type of normative consideration that I have identified and will discuss later in the paper. More reflective lawyers, however, as well as many legal theorists, do have a more robust conception of rules which contrasts them with other normative standards such as values and reasons. ${ }^{5}$ There is, of course, a ready model for such a robust conception of rules in the law provided by the analogy of statutory rules, and it is the legislative analogy which has continually inspired the more theoretically informed accounts of the conventional view of precedent. ${ }^{6}$ The basic propositions of the conventional view can be filled in with this model in mind:

$(1 *)$ Precedents lay down rules in their rationes, and such rules are binding in later cases whose facts fall within the scope of those rules.

That is, precedents lay down rules (rationes) in their judgments-just as statutes lay down rules in their provisions-and such rules are binding in later cases whose facts fall within the scope of those rules. Statutes and precedents simply employ a different process for laying down rules.

\footnotetext{
${ }^{4}$ Those familiar with Raz's account of rules as 'protected reasons' may be particularly drawn to this conclusion. I will explain later why even on this account there is an important difference between rules and rationes.

5 e.g. Cross and Harris 1991, 72; MacCormick 1987, 170; Bell 2000, \$\$ 1.63-1.79;

Raz 1979, 183-9; Alexander 1989; Schauer 1991, 181-7.

6 E.g. Raz 1979, 195; Alexander 1989, 23; MacCormick 1994, 213-28.
} 
$\left(2^{*}\right)$ Some later courts have the power to overrule precedents, but all later courts have the power to distinguish precedents, which amounts to a limited power to modify the rule laid down in the precedent case.

That is, some later courts enjoy the power to repeal the rationes of earlier precedents, whereas all courts enjoy a limited power to amend the rationes of a precedent case.

$\left(3^{*}\right)$ The application of the rule in later cases is determined by the precedent court's justification(s) for the rule.

That is, the later court determines the application of the precedent's ratio by reference to the best understanding of how the precedent court meant the ratio to be applied, just as the application of a statute is deferential to the legislator's supposed purpose in passing the enactment. In both cases the court's application of the legal rule must be faithful to the intentions of the law-maker.

$\left(4^{*}\right)$ The function of the doctrine of precedent is to create new legal rules to settle uncertainty in the law, so as to provide guidance to individuals and the courts.

That is, the function of the doctrine of precedent is to enable courts to create legal rules to provide guidance for individuals and later courts. The courts' role is akin to delegated law-makers exercising directed powers: they must decide cases by creating a new rule which best furthers the purpose(s) of the area of law in question.

Statutes and precedents differ, of course, because legislators enjoy far wider discretion in what they can do (and what considerations they can act on), but as to the type of normative standard which they create, they are on a par. The assimilation of precedent to statute facilitates a unified account of law in common law systems: the basic building blocks of legal doctrine are legal rules.

Adopting this perspective, what can we learn about the nature of legal rules? On a formal level, rules possess an antecedent- 
consequent structure, ${ }^{7}$ i.e. they can be represented in the following manner:

$$
\mathrm{R}=\text { If } A \text { then } C
$$

$A$, the antecedent, lays down the set of conditions which are individually necessary and jointly sufficient to entail the conclusion (e.g. $\left.A=\left\{\begin{array}{lll}J, K & L\end{array}\right\}\right)$. In a simple case $C$ will denote some consequence such as being under a duty (e.g. to pay damages), possessing a right (e.g. to terminate a contract), or being subject to a liability (e.g. to five years imprisonment on conviction). In a more complex case, $C$ may simply be one step towards these conclusions, as in the case of a constitutive rule. ${ }^{8}$

Rules have a certain form which is related to their distinctive role in decision-making. Where a binding rule exists, it determines (prima facie) the normative outcome whenever some situation falls within the scope of the antecedent. When correctly applied to a situation which falls within the scope of the antecedent, it is the fact that there is a valid rule which justifies reaching the conclusion. The rule, then, is the justification for deciding that $C$. Decision-making guided by rules is normally contrasted with decisions made on the balance of all relevant reasons. ${ }^{9}$ A decision-maker acting on the balance of all relevant reasons is simply trying to make the decision in the case which is correct, all things considered. What is the correct decision will depend, in part, on the ramifications of deciding the case in favour of one of the parties, including how others will be affected by it, but decision-makers can take every relevant reason into account in reaching their decision. Where a decision-maker is using a rule, by contrast, the decision $C$ is required if the case falls within the scope of the antecedent, even in cases where the decision-maker judges that the balance of reasons absent the rule (which might be called the 'underlying reasons') do not

7 See Alexander 1989, 19; MacCormick 1994: 45; Raz 1990: 50; Schauer 1991: 23 4.

8 These symbols are used merely for the sake of clarity: they are not a representation of the claims in predicate, propositional, or any other type of logic. The capital letters stand for general conditions, whereas lower-case letters stand for particulars which satisfy the general condition (i.e. $J$ stands for the general feature, whereas $j$ stands for a particular with that feature).

9 There are other ways of setting up a decision-making process, but for the purposes of this discussion these alternatives can be put to one side. 
support $C$. Rules, then, operate in a manner which is sub-optimal for some individual decisions, and alter the reasoning by which the decision-maker reaches its conclusion.

In a variety of contexts, including law, rule-based decisionmaking is thought to have a range of advantages over reason-based decision-making, depending on the content of the rule and the abilities of the decision-makers using them. The central advantage, which supports many others, may be described as 'replicability'. ${ }^{10}$ Decisions based on well-cast rules used by competent decisionmakers can be replicated by both the decision-makers themselves and by others, and they are often far easier to replicate than the decisions which the same decision-makers would reach on the balance of underlying reasons. Where this is the case, decisionmaking using rules will be far more reliable and predictable than decision-making on the basis of the underlying reasons. Replicability also facilitates transparency-the ability of those affected by the decision to recognise that it accorded with the rule-which can serve to maintain confidence in decision-makers. Equally it can promote accountability, by making it easier to assess the competence and integrity of decision-makers. Finally, the use of rules can help to reduce the problems which arise when a number of decision-makers disagree about the identity and significance of the underlying reasons. ${ }^{11}$

Rules achieve these advantages by focussing attention on the question whether the conditions contained in the antecedent are satisfied, rather than on attempting to determine the balance of underlying reasons in each case. Obviously they do not eliminate uncertainty, since there is still room for disagreement over (a) the proper application of the antecedent in particular cases (i.e. determining the scope of the rule), (b) how to resolve conflicts with other rules, and (c) when to recognise exceptions not already enumerated in the rule. But to the extent that any disagreements over the resolution of (a), (b) and (c) do not render the decisionmaking less replicable than direct resort to the balance of underlying

10 The term is borrowed from Eisenberg 1988: 10-12.

11 Rules may also be advantageous if the decisions made using them will (over a range of cases) accord better with the underlying balance of reasons than decisions made directly attempting to apply those reasons. But the epistemological basis needed for making these two judgements is frequently absent. 
reasons would, rule-based decision-making is correspondingly advantageous. This is a contingent question, but it is generally thought that the use of legislative rules manifests these advantages, and I will accept this assessment in the remainder of this paper.

There are three situations, then, where a rule may fail to control a case which, on the face of it, falls within the scope of the rule. The least important for our purposes is (b), where there is a conflict with other legal rules. Where such a conflict occurs, the court must find a way to reconcile the rules, but it does so by either finding some interpretation of one or the other (or both) rules which avoids the conflict, or regarding one as prevailing over the other in that type of case. The other situations arise where the rule points to a result in a case which the court regards as unsatisfactory. The two methods open to the court to avoid that result are (a) reinterpretation of the scope of the rule and (c) the recognition of unenumerated exceptions. It can hold that the scope of the rule, properly understood, does not cover the case in hand, i.e. that on the proper interpretation of the rule it does not extend to the facts of the case. Alternatively it can recognise a novel exception to the rule. Courts regard the reinterpretation of rules as easier to justify than the recognition of exceptions, and thus prefer to base their decisions on that approach. They also think, however, that there are limits to reinterpretation, so that it is not always possible to interpret a statutory rule in such a way that it avoids a result which the court regards as unsatisfactory. And they also think that the fact that they would have decided the case differently if they had been deciding on the basis of the underlying reasons is not in itself sufficient to make the result unsatisfactory.

These points about the nature of rules can be captured in a number of ways, for example by Schauer's analysis of rules as 'entrenched' generalisations ${ }^{12}$ or Raz's proposal that they 'exclude' other considerations. ${ }^{13}$ What is characteristic of a rule is that the result it requires is resistant to being avoided simply because the underlying reasons in a particular case do not accord with what the rule requires. Statutory rules are defeasible, i.e. capable of giving way to other considerations, but it is nonetheless true that they

12 Schauer 1991, especially chapters 3-5.

${ }^{13}$ Raz 1990, 73-84. 
generally determine the result in those cases that fall within their scope. So when it is true that the facts in a case fall clearly within the scope of the antecedent $\{J, K, L\}$, the only further question is whether the result would be so unsatisfactory that the court should consider whether an available interpretation of $J$, or $K$, or $L$ would avoid that result, or whether the case should be treated as an exception.

From this perspective it is easy to see why distinguishing has been thought to be the most difficult feature of the common law doctrine of precedent to reconcile with the conventional view of rationes as rules. ${ }^{14}$ Distinguishing is the practice whereby later courts cite some difference between the facts of the precedent case and the facts of the later case to explain why they are not following the precedent. A later case may clearly fall within the scope of the earlier ratio, i.e. it may be a straightforward case of $\{J, K, L\}$, but the later court may decline to reach the result $C$ on the basis that there is some feature in the later case, not present in the earlier case, which provides a good reason not to reach the result $C$. For example when a former member of a violent criminal organisation sought to rely on the defence of duress to a criminal charge under English law, it was held that the defence was not available because the defendant had voluntarily exposed himself to the risk of such threats, despite the earlier formulations of the defence mentioning no such restriction on the availability of the defence. ${ }^{15}$ The existence of distinguishing raises two problems for the conventional view of precedent. The first is whether it is compatible with the idea that rationes are rules (in the robust sense akin to statutes). The second is whether there is a satisfactory rationale for the practice from a rule-based perspective.

There are two ways in which distinguishing has been argued to be compatible with rule-based decision-making. The first is to claim that rationes are rules which generally control cases within their scope, but to argue that ascertaining the scope of a ratio is an extremely difficult matter. On this approach, distinguishing is really a form of reinterpretation, which seeks to make the ratio more closely

14 Simpson 1973, 372; Perry 1987, 227-9; Moore 1987, 185; Schauer 1989, 455.

15 Sharp [1987] 1 QB 853 (Court of Appeal): the earlier decision Graham (1982) 74 Cr App R 235 (Court of Appeal) had been endorsed by the House of Lords in Howe [1987] AC 417. 
match the justification for the rule. This view of distinguishing is vulnerable on two fronts. As many theorists have observed, it makes the identification of the ratio sound far more mysterious than legal practice warrants. ${ }^{16}$ In many precedents the ratio is easily identifiable, even if its application to later cases may be controversial. In other cases the level of generality of the factors $\{J$, $K, L\}$ is left quite vague, or the category is not characterised except by example. ${ }^{17}$ This inevitably leaves greater leeway to later courts in characterising the ratio. And there are, of course, some decisions where it is extremely difficult to follow the court's reasoning, or to identify the basis on which they reached the result in the case, but it would be a mistake to suppose that all of this showed that the identification of the ratio is such a complex task. There simply are cases where the ratio is not precisely specified, or where the reasoning is muddled, confused or unclear, i.e. where the judgment is unsatisfactory. On the other hand, if one thinks the ratio so difficult to ascertain, and so closely tied to its justification, it can be argued that it makes better sense to abandon the idea that the ratio constitutes the binding part of a precedent. What is really doing the work in precedents is the justification for the ratio, and the ratio is perhaps best seen as a useful shorthand for the more detailed justification for the result in the case. ${ }^{18}$

Instead of supposing that distinguishing is a form of reinterpretation, the more promising response for the rule-based model is to characterise distinguishing as a power enjoyed by courts to amend the ratio of a previous case, thereby changing the rule in such a way that the present case falls outside its scope. While only some courts have the power to repeal the ratio of a precedent caseby way of overruling the decision-all courts enjoy the more circumscribed power of amendment. The challenge to this line of response is whether the constraints on distinguishing are strong enough to make precedents generally determinative of cases falling within the scope of the ratio, in a way similar to statutory rules. Distinguishing is certainly subject to some constraints: the later

16 See e.g. Simpson 1961, 168-9; MacCormick 1994, 82-3; Raz 1979, 184;

Eisenberg 1988, 51-61.

17 See Levenbook 2000, 201-11.

${ }^{18}$ For two different approaches of this kind, see Dworkin 1978, 110-11 and Perry $1987,235$. 
court must point to some difference between the facts of the two cases which it regards as providing a good reason for not following the result in the precedent. This can be represented as follows: if the ratio is

$$
\mathrm{R}=\text { If }\{J, K, L\} \text { then } C
$$

Then the later court must (1) only alter $\mathrm{R}$ by adding a new element to $\{J, K, L\}$ (or by substituting a sub-category of $J$, or $K$, or $L$, for that element), thereby narrowing the scope of $\mathrm{R}$, and (2) the amended rule must not be inconsistent with the result in the precedent case. So if the facts of the case are:

$$
\mathrm{F}_{1}=\left\{g_{1}, h_{1}, i_{l}, j_{1}, k_{l}, l_{l}\right\}
$$

then $\mathrm{R}$ can be altered by adding some novel factor $M$, but it cannot be altered by adding $\sim G$ or $\sim H$ or $\sim I$, since the modified ratio would no longer support the result in the precedent. Taking the example of duress discussed above, none of the preceding cases had involved a member of a violent criminal gang, thus it was permissible to add the condition that the defendant had not knowingly exposed himself to the risk of the duress. The results of the earlier cases would have been unchanged by this additional condition. By contrast, it would not have been possible to add a condition that those involved in any criminal enterprise could not avail themselves of the defence, as earlier cases had allowed such people to raise the defence.

These two constraints, however, are too weak in themselves to make precedents generally determinative. Whenever a later court thinks that the facts of its case do not justify the result indicated by the ratio, it need only cite some factual difference between the cases which it views as providing a good reason against that result to distinguish the precedent. It will only be blocked from doing this when it can see no difference which provides a good reason against reaching the precedent's result. This will not be a common state of affairs. Of course, precedents will often be followed-because there are many cases where the later court agrees that the result indicated by the precedent is justified on the facts before it. The 'constraint' of precedent, however, lies in those cases where the later court does not agree that the facts before it justify the result 
indicated by the ratio, and here the doctrine of distinguishing provides an easy way to reach its preferred result if the only constraints are (1) and (2). With only these constraints, instead of the ratio generally determining the result in future cases, it merely restricts the ability of the later court to reach the result it regards as justified on the facts (i.e. the result which it would reach were there no precedent). What is more, it restricts the later court in a fairly haphazard manner, turning on what facts happened to be present in the precedent case (or, more precisely, which facts are mentioned in the decision in the precedent case).

On the rule-based view of precedent, then, there must be some additional constraint on the power of later courts to distinguish precedents. Two possibilities have been floated: (3a) there is a presumption against amending the rule, just as there is in the case of overruling proper (and in the recognition of statutory exceptions)the rule must not merely be regarded as wrongly formulated, but the later court must only modify it when the improvement to the rule passes a certain threshold ${ }^{19}$; or $(3 \mathrm{~b})$ that the new rule must preserve the 'fundamental rationale' of the original rule, i.e. justify its decision 'by reasoning very similar to that justifying the original rule'. ${ }^{20}$ Either would succeed in making the power of amendment limited enough to make rationes generally applicable in future cases. Unfortunately for the rule-based view of precedent, the practice of distinguishing in the common law does not conform to either constraint.

Looking first at (3a), it is simply not characteristic of common law courts to approach distinguishing in the same spirit as they approach overruling. Unlike courts faced with the question of overruling a precedent, distinguishing courts do not proceed as if there was a presumption against distinguishing even when it is consistent with earlier authorities and would produce a better result. Instead later courts simply concern themselves with whether it would be consistent with the facts in earlier decisions, and whether

19 This is derived from Schauer 1989, 469-71, though Schauer's proposal is more closely tied to Eisenberg's account of the common law (1988).

20 The quotes are from Raz 1979, 188 and 187. Raz qualifies the later statement by saying that a modified rule 'can usually be justified only be reasoning very similar to that justifying the original rule' (emphasis added), but it is unclear what situations this covers. 
it would be a better decision. If those two questions are answered positively, there is no further question of whether the court should nonetheless decline the invitation to distinguish.

What of the second proposal (3b) - that courts may only distinguish in ways that preserve the 'fundamental rationale' of the original rule? What this might mean is this: a later court is bound by the justifications and reasons given by the precedent court for the ratio in the case. So a new factor can only be introduced into the ratio if the precedent court's own justifications for the rule would make it relevant, or if the precedent court would have assessed it as providing good reasons for qualifying the rule. On this approach, then, the function of the later court is to modify the ratio so that it better reflects the precedent court's justification: in a sense that justification is the real rule, and the ratio is just an on-going attempt by the courts to properly capture the justification. ${ }^{21}$

However, this limitation also does not seem to be borne out by legal practice. Courts are bound to consider the legal conclusion on which the result in the precedent case was based, and must treat that conclusion as correctly decided. The precedent court's justifications are relevant to ascertaining what was concluded (i.e. in ascertaining the exact content of the ratio), but are not themselves binding on lower courts. There are many situations in which later courts ignore or discount some of these justifications; there are even cases where later courts find no compelling rationale at all for the legal doctrine on which a precedent was decided. ${ }^{22}$ One example must suffice. The growing recognition of the doctrine of unjustified enrichment in English law has led to the reinterpretation of a number of doctrines which were historically said to be grounded on 'quasicontract', i.e. some kind of counterfactual contract between the parties. Doctrines such as frustration, it is said, are regarded as better supported in terms of the court preventing one party being unjustly enriched at the other's expense, than in terms of an 'implied

21 As Simmonds notes $(1984,112-14)$, this makes the view quite similar to the tradition which holds that distinguishing is simply a case of reinterpretation-a tradition Raz rejects $(1979,183-5)$.

22 See the English cases on the 'marital exemption' to rape claims, discussed in the decision of the House of Lords which finally abrogated the exemption: $R v R$ [1992] 1 AC 598. The rationale for this exemption was said to have been that marriage constitutes an irrevocable consent to sexual intimacy—a view flatly rejected by the House of Lords. 
contract' between the parties. ${ }^{23}$ Many innovations in legal justification have their origin in academic theorising, and the endorsement of these views is not restricted to cases where the court is empowered to overrule earlier precedents.

The plausibility of the claim that later courts are bound by the precedent court's justification comes in part from the fact that later courts frequently do adopt the arguments of their predecessors. But the explanation for this is not that they are legally bound to do soit is simply that there are many cases where they are persuaded of the merit of the justifications or are content to adopt them. And the explanation for this agreement lies in the fact that the precedent court and later court are members of the same legal community and share a great many assumptions and understandings about the law. All lawyers undergo a process of legal education which operates as a form of enculturation. Employment and promotion through the legal profession turns in large part on having successfully internalised the prevailing legal outlook. Given all this, it would be very surprising if one court's justification for its decision was wholly unpersuasive to another. And so it makes sense for a later court to examine the precedent court's justification, since it is often likely (on the whole) to be acceptable. This tends to break down, however, where authorities are very old (e.g. the marital rape exemption) or the area of law is a site of considerable controversy (e.g. some countries' constitutional law) or a judge is very independently minded. ${ }^{24}$

The impression that later courts are bound by the justifications given by their predecessors is also due to the fact that later courts can reject the application of a precedent by either interpreting the ratio more narrowly, or by distinguishing, and these two methods are not always kept distinct in the judgment. So it may be argued before the later court that either (i) the ratio, properly understood, is inapplicable to the facts of the case, or (ii) even if it is, it can be distinguished. It is (i) which corresponds to proposal (3b). The

23 See Robert Goff J's judgment in BP Exploration v Hunt (No.2) [1979] 1 WLR 783 (Queen's Bench Division). I don't mean that this is a better rationale: merely that the courts have abandoned the earlier rationale.

${ }^{24}$ This provides a simpler explanation for the way principles are treated than Perry's argument that while courts are bound by the principles the precedent court relied upon, just how binding they are depends upon multiple 'weighing' factors: 1987, 241-3. 
later court may re-examine the precedent and conclude that its ratio does not apply to the facts of the new case: contrary to what might be surmised from what the precedent court said at a number of places, its own justification for its decision only supports a ratio which does not cover the new case. In practice the later court will often blur the question of whether they are doing (i) or (ii), since it does not matter which it is in the end. Those judges who are particularly deferential to their colleagues, or staunch believers in judicial comity, may prefer to couch their conclusion in terms which suggest re-interpretation, even if what they are doing is more plausibly a case of distinguishing.

The reliance by the later court of its own understanding of the justification for the ratio of the precedent case is also consistent with other aspects of legal practice. The creation of exceptions in statutory interpretation is rarely thought to be restricted to exceptions which would in fact have been adopted by the legislator or which are justified by the rationale for the statute. Where a new exception is created the court determines for itself whether the case for excepting some situation is compelling. (Again, some judges may profess a more deferential attitude to the legislature, and cast their arguments in terms of what the legislature 'must' have intended, but other judges do not, and even those who are deferential rarely do more than assert that this is how they reached their conclusion.)

The fact that later courts act on their own assessment of the justification for the ratio in the earlier case means that the weakness of conditions (1) and (2) on distinguishing is not dispelled. The later court is free to distinguish whenever it judges that the facts of the case before it do not favour $C$, so long as the distinction is consistent with the result on the facts in the precedent case. The effect, then, is that where a situation falls within the ratio of a precedent case, the later court is only prevented from reaching its favoured outcome where the distinction would be inconsistent with the result in the precedent case. Rationes, instead of generally determining the outcome as rules would, seem merely to be haphazardly restricting courts from reaching the outcome they judge best absent the precedent. 
Thus the operation of distinguishing is difficult to reconcile with rule-based decision-making. Restrictions (1) and (2) are too weak to make rationes generally determine the results in later cases. This leaves the other problem for the conventional account of precedent: what is the point of the practice of distinguishing on a rule-based approach? What value would be served by allowing later courts to amend a rule so that it does not apply to the facts in the case before the court? Like many other aspects of the law, it might be thought that the point of distinguishing is to strike a balance between rigidity and flexibility in the common law. Later courts should be free to make amendments to common law rules in situations where a too rigid adherence to rules would lead to injustice. The sacrifice in replicability is justified by the gain in doing justice to the parties before the court. The problem with this proposal is that distinguishing strikes this 'balance' in such an odd way. A balance between rigidity and flexibility would seem to point to two features lacking in distinguishing: (a) a presumption against altering the ratio, just as there is a presumption against creating exceptions to statutory rules and against overruling precedents, and (b) a freedom to alter the ratio even where it would have the consequence that an earlier case would now be decided differently. After all, why should the facts of the precedent case which do not form part of the precedent's ratio play any role in later deliberations?-all it seems to achieve is an arbitrary restriction on improving common law rules.

The way that the doctrine of precedent operates in the common law, then, is difficult to square with the virtues normally associated with rule-based decision-making. The problems of distinguishing are compounded by the fact that the courts do so little to assist in the construction of rationes from their judgments. Why are common law judgments so discursive at the appellate level? Why do they devote so much space to a detailed statement of the facts when their aim is to create a new legal rule to settle some controversial issue in dispute between the parties? Of course, one can say that this is just the continuation of a historically embedded practice, but why has it been sustained by all common law jurisdictions? It is to answer these types of questions that a different approach to the nature of precedent is called for. 


\section{Case-by-case decision-making}

A better understanding of the doctrine of precedent must start at a different place-with cases rather than rationes. Any satisfactory view of precedent must see distinguishing as an integral part of it, rather than as an add-on or quirk of the common law

A different way to understand precedent is in terms of cases resolving particular disputes before the court, and giving grounds which are sufficient in those circumstances to justify the result. The grounds it gives are, by their very nature, general features of the situation, and so the decision commits the court to deciding any case with the same facts in the same way. So in the precedent case $\left(\mathrm{P}_{1}\right)$ the facts may be:

$$
\mathrm{F}_{1}=\left\{g_{l}, h_{1}, i_{1}, j_{l}, k_{1}, l_{l}\right\}
$$

and the grounds sufficient for the result may be:

$$
\mathrm{R}_{1}=\text { If }\{J, K, L\} \text { then } C
$$

If there was a case $F_{n}$ with the facts:

$$
\mathrm{F}_{\mathrm{n}}=\left\{g_{n}, h_{n}, i_{n}, j_{n}, k_{n}, l_{n}\right\}
$$

then the court would regard $C$ as the justified result in $F_{n}$ as well. Of course, cases come before courts with all of their multitudinous facts, hence this type of situation with exactly the same facts will not occur in practice. This raises two questions: (a) when is $F_{1}$ relevant to a case which is not exactly the same on the facts? and (b) in what way is it relevant?

The fundamental requirement of the common law doctrine of precedent, it will be recalled, is that earlier decisions must be treated as correctly decided on their facts. What is the significance of this for $\mathrm{P}_{1}$ ? What the court decided was that in the context of $\left\{g_{l}, h_{l}, i_{l}\right.$, $\left.j_{1}, k_{l}, l_{l}\right\}$ the features $\{J, K, L\}$ justified the conclusion $C$. There are two aspects to what the court decided. The first is that the presence of features $\{J, K, L\}$ provided a sufficient reason to conclude $C$. The second is that the presence of the other features $\{G, H, I\}$ did not defeat the reason provided by $\{J, K, L\}$. 
So the answer to (a) is that any case which includes the facts $\left\{j_{n}\right.$, $\left.k_{n}, l_{n}\right\}$ will be regarded as similar to $\mathrm{F}_{1}$, and require the consideration of $\mathrm{P}_{1}$. The court in $\mathrm{P}_{1}$ held that the presence of features $\{J, K, L\}$ was sufficient to justify $C$, and so it held, in effect, that where the facts $\left\{j_{n}, k_{n}, l_{n}\right\}$ are present there is a sufficient reason to conclude $C$. Whenever a later case includes facts $\left\{j_{n}, k_{n}, l_{n}\right\}$ then, the situation is like $\mathrm{P}_{1}$, and $\mathrm{P}_{1}$ must be considered by the court. The answer to (b) is that a later court must ask itself whether any of the facts in the case before it provide reasons which defeat the justification in $\mathrm{P}_{1}$ for $C$, i.e. whether any of the features of $\mathrm{P}_{2}$ provide reasons which defeat the reason(s) provided by $\{J, K, L\}$. If they do, then $\mathrm{P}_{1}$ should be distinguished; if not, then $\mathrm{P}_{1}$ should be followed. Take the case $\mathrm{P}_{2}$ with the following facts:

$$
\mathrm{F}_{2}=\left\{\sim g_{2}, h_{2}, i_{2}, j_{2}, k_{2}, l_{2}, m_{2}\right\}
$$

In this case, unlike the precedent case, feature $G$ is absent, but additional feature $M$ is present. The question that must be answered is whether these differences provide some reason defeating the reasons given by $\{J, K, L\}$ for $C$. This question must be answered from the point of view of the later court: it must consider how strong the reason provided by $\{J, K, L\}$ for $C$ really is, and whether it is defeated by any reason(s) based on the absence of $G$ and the presence of $M$. In comparing the two cases the later court regards any fact such as $M$ not mentioned in the precedent (or not implied by it) as having been absent. It is the decision of the precedent court on the facts reported in the judgment-not the true facts-that binds the later court, but where the precedent court has not stated that it considered certain factors the later court is free to do so. ${ }^{25}$

Understood in this way, the common law doctrine of precedent starts to take shape. What binds later courts are precedents, not rationes. The ratio of a judgment is merely one aspect of the decision, and is silent on the other significant dimension. Teachers of law are only too familiar with this: the standard error of the novice student

25 This explains the judicial practice noted by Raz 1979, 187; cf Alexander 1989, 42-4. The clearest example of precedent operating on the facts as reported in the case rather than the actual facts are striking out applications, where the court decides that the plaintiff's allegations, even were they to be proved, do not disclose a cause of action. 
is the belief that all they need to know about a case is its 'holding' or 'ratio', and that for this purpose an accurate headnote will suffice. Why bother ploughing through the careful consideration of the facts and the various arguments considered by the court when all we need to know is the rule for which the case is authority? Once identified, the rule can be routinely applied, save for penumbral problems of interpretation. Weaning students off this simplistic understanding of the common law is one of the most important tasks in their legal education.

In addition, what it means to be bound by a precedent is that a later court must either follow a precedent or distinguish it. This is another staple of the legal classroom. Students are presented with various hypotheticals to test their understanding of legal doctrine. The hypothetical falls squarely (not peripherally) under what was said in an earlier case and might be thought to be a straightforward application of the decision. But instead questions are raised whether it is not easily distinguishable from that case: here the person did not know some crucial fact, or the other party had concealed something, or the agreement is a consumer transaction, or the defendant was mistaken about the significance of their acts. Appreciating how to distinguish, how to see the relevance of the facts in the earlier case, is integral to understanding how the doctrine of precedent works. The point is not that it is easy to create new exceptions to the ratio in the earlier case, but rather that the earlier case did not purport to settle (even prima facie) the result on relevantly different facts.

It might be argued, on the other hand, that there is a good basis for drawing a contrast between following and distinguishing, and for holding that the fundamental requirement of precedent is to follow the earlier case, with distinguishing as merely an exception. The argument is that there is a highly significant asymmetry between following and distinguishing. When a precedent is distinguished, the law changes, whereas when it is followed, it stays the same. So the law is what is found in the ratio: when it is followed the ratio stays the same, whereas when it is distinguished the ratio is alteredand it is only in the latter case that new law is being made. But this is a mistake: the line of thought simply presupposes that what is binding in a precedent is the ratio. It is important to see the symmetry of following and distinguishing: every time a precedent is 
followed the legal doctrine of which it is a part is altered. On the conventional view, following a precedent simply shows that the court did not exercise its power to amend the rule, and so the rule was simply 'applied' without modification. But this overlooks the other crucial dimension of precedents - the role of the facts in a case. Every time a precedent is followed further facts are added to the list of those regarded as insufficient to defeat the reason provided by the ratio. So following, just as much as distinguishing, changes the law (not the ratio). Distinguishing is not akin to statutory amendment: it adds further detail to doctrine, rather than altering what was established in an earlier case. ${ }^{26}$ Nor is distinguishing based on a 'power' to 'amend' rationes: it is simply the upshot of considering the relevance of an existing precedent.

None of this means that the ratio of a judgment is superfluous, and that all that matters are the facts of the case and the result, or the principles that justify the result. Later courts are bound by precedents only when the facts of the later case fall within the scope of the ratio of the precedent. The ratio sets a limit to the binding scope of the precedent: not that earlier decisions are irrelevant to cases that fall outside the ratio, rather their significance is by way of analogy, not precedent. Furthermore, the ratio sets out the factors that ground the reason(s) in favour of the result: the later court must determine the strength of the reason in favour of the result in the precedent on the basis of those factors. ${ }^{27}$

Precedents, then, are quite unlike statutory rules. This is not because rationes have to be constructed from judgments. ${ }^{28}$ The rules created by a statute are not identical with the text of the statute: statutes create legal rules, but the rules they create also have to be constructed. It is just that there is a more established method for

\footnotetext{
${ }^{26} \mathrm{Nor}$ is it a response to this point to say that there could be a case with identical facts which did not have this effect. The class of cases with identical facts is an empty set in reality; and in any case it leaves the problem of explaining how all those other 'rule-applying' situations manage to change the law.

27 The role of the ratio might suggest some affinity with Alexander's taxonomy of rule/result hybrid views of precedent $(1989,44-5)$, except that the reason-based view of precedent is not a hybrid using rules, but a unified account of case-by-case decision-making.

${ }^{28}$ Contrary to a common objection: Simpson 1973, 372; Moore 1987, 185-6; Perry 1987, 235-7; Schauer 1989, 455.
} 
doing this in the case of statutory rules than with rationes. ${ }^{29}$ Precedents are different because they are context-dependent whereas statutes are context-independent. A precedent is a decision which is sufficient in the context of the case to reach a decision-it does not purport to pre-empt the conclusion in other contexts, though in being based on general considerations it necessarily has a relevance to other contexts. A statute is not (normally ${ }^{30}$ ) a decision on a particular set of facts-it applies to all situations which fall within its scope and lays down a prima facie solution to all of those situations.

How might precedents be conceptualised, then? One possible analysis is that they amount to protected reasons, in Raz's terminology. ${ }^{31}$ A protected reason is the systematic combination of a first-order reason and an exclusionary reason. An exclusionary reason is a second-order reason not to act for certain first-order reasons. The effect of the exclusionary reason, then, is to 'protect' the first-order reason from being defeated by certain (classes of) other first-order reasons. Applying this analysis to precedents, the ratio would provide the basis for the first-order part of the protected reason. The other facts of the case would provide the basis for the exclusionary reason: later courts are excluded from relying on reasons provided by features that were present in the precedent case to defeat the first-order reason for the result. I introduce this way of understanding precedents not to endorse it as the only way to capture their effect, but to meet one line of potential criticism which could be raised on the back of it. It might be argued that protected reasons are norms, and that protected reasons which are general (unlike, say, a specific order made in one situation) just are rules. ${ }^{32}$ So if precedents can be represented as protected reasons and have general application, then precedents are rules after all. In one sense this is unobjectionable, but in a more important sense it is quite misleading. If one wishes to stipulate that (general) protected

${ }^{29}$ As Simpson noted: 'There may indeed be as many ways of finding the ratio of a case as there are ways of finding a lost cat.' $(1961,159)$.

${ }^{30}$ Note by contrast legislative acts such as Bills of Attainder.

31 On protected reasons see Raz 1979, 16-19 and 1989, 1160-2. On exclusionary reasons see Raz 1990, 35-48, 73-84, 178-99; 1989, 1154-79.

$32 \mathrm{My}$ understanding is that Raz claims that rules are general protected reasons, not that all general protected reasons are, ipso facto, rules. 
reasons are 'rules' then, of course, precedents are 'rules' as stipulated. But when theorists speak of the common law as rules they are thinking of something different to just any type of general protected reason. The inspiration behind most accounts of precedents as rules is the statutory analogy. Since it is only an analogy there is no need for precedents to share all of the features which characterise statutory rules, nor to be as 'strong' as they are. But the normal claim has been that they do in fact share the same features as statutory rules: the main difference has always been located in the courts having the 'power' to distinguish. Precedents differ from statutory rules simply in virtue of the power of lower courts to distinguish them in some restricted situations. ${ }^{33}$ This assimilation of precedent to statute is important for many discussions of law, since many claims that are made about the nature of law are based on the statutory model of rules, and precedents are generally subsumed under this model. But even if one agrees that both statutes and precedents create protected reasons, the differences between them are more significant than the similarities. Both create first-order reasons in favour of $C$ when certain conditions are satisfied. But statutes entrench this reason because of a general presumption against its being defeated by any of the underlying reasons in a situation. So these are excluded unless they are above a certain (considerable) threshold of weight. By contrast, precedents exclude, absolutely, reasons based on factors present in the precedent case from defeating the first-order reason. So the precedent is 'protected', but in a highly selective manner. In terms both of the degree of protection, and the range of protection, precedents are quite distinct from statutory rules: the degree is absolute not presumptive, whereas the range is piecemeal, not general. And it is this that explains why courts recognise exceptions to statutes but distinguish precedents. On the conventional view of precedent, distinguishing is assimilated to the power to recognise novel exceptions to statutory rules: effectively, a power of amendment. But on the case-by-case view of precedent, distinguishing is an integral part of common law reasoning-part and parcel of what it is to reason from precedent.

${ }^{33}$ Raz 1979, 188-89; Schauer 1991, 187. The power to overrule is even more limited in operation. 
If the case-by-case view of precedent is correct, however, what would explain the popularity of the conventional view? It may be that practising lawyers do not exactly mean to commit themselves to the robust conception of rules, but the idea that the common law (e.g. contract law, torts, trusts) involves 'rules' is widely held, as is the idea that there is some important similarity between what statutes and precedents do.

There is a mixture of reality and appearance to the idea that the common law is a system of rules. The reality rests on the fact that precedents in the common law do not come singly, but in groups. We speak ordinarily of certain 'doctrines' of the common law, of certain 'institutions' (such as the trust) and of particular 'causes of action' (for breach of contract, assault, receipt of trust property ...). A common law doctrine is the upshot of many precedents and their combined effects. Now a line of cases on some issue can indeed bring it closer to the nature of a rule. As more cases are decided (including both distinguishing and following), there are a wider range of decisions from which the conditions calling for the result can be distilled, and a wider range of factual conditions blocking the practice of distinguishing. So after cases $\mathrm{P}_{1}$ to $\mathrm{P}_{10}$, the legal position may be expressed in the following way:

Doctrine $=$ If $\{J, K, L, \sim M, \sim N\}$ then $C$

while the facts considered insufficient to defeat the doctrine now amount to:

\section{$\{A, B, C, D, E, F, G, H, I, O, P, Q, R, S\}$}

This does not, of course, exclude novel cases from arising and raising novel questions, but it does extend the range of features that cannot be relied upon to distinguish the doctrine. This does not reach the generality of statutory rules, but it does mean that a wider range of situations will not be able to be distinguished.

There is another reason why a range of cases following and distinguishing a precedent make it more 'protected'. The fundamental requirement of the doctrine of precedent, as we have seen, is to treat earlier cases as correctly decided. Now if a court is faced with a novel case falling within the scope of a doctrine where it thinks the merits do not support $C$, it may be able to distinguish 
on the basis of some previously unreported fact $t_{11}$. But the court may also think that feature $T$ provides no better argument against $C$ than that provided by another factor which has already been rejected as a basis for distinguishing. To distinguish on the basis of some fact which the court regards as providing no better argument than another fact that has already been rejected would be to imply that an earlier case was wrongly decided. So the effect of earlier decisions is broader than simply excluding reliance on facts present in the earlier cases as a basis for distinguishing. ${ }^{34} \mathrm{~A}$ later court is not free to distinguish on the basis of any factual difference between the case before it and the precedent: if the difference provides an argument of the same kind as a fact that has already been rejected, then the argument must be a more compelling one. It is different, of course, if the argument provided by the novel fact(s) is not of the same kind as that raised by the facts of earlier cases. To distinguish on this basis would not be inconsistent with the correctness of the earlier decisions. ${ }^{35}$

The operation of the doctrine of precedent, then, can make legal doctrine more 'rule-like' than it is when one looks at an individual precedent in isolation. This is particularly true of those areas of the common law which have remained relatively uncontroversial over long periods of time, such as the law of trusts or the tort of trespass, or particular doctrines within certain areas, such as common law offences like murder and assault. In areas of greater controversy, by contrast, there will have been more interventions by appellate courts overruling precedents (as well as statutory interventions), so there will have been more disruptions to lines of cases. In areas such as the tort of negligence, for example, where common law courts have struggled with the duty concept and with the scope of recovery for pure economic loss, the law does not

\footnotetext{
${ }^{34}$ Of course, courts sometimes rationalise a distinction with arguments they would not give were there not a precedent blocking their preferred argument. This may help to explain the phenomenon of 'jagged' development in common law doctrine discussed by Eisenberg 1988, 70-4.

35 This explains how later courts can make decisions on the merits of distinguishing even when they disagree with the outcome of the precedent case (cf Alexander 1989: 34-7). They determine the strength of the reason provided by the ratio that has to be defeated and consider whether a purported distinction provides either (a) a better reason than one already rejected or (b) a different type of reason.
} 
appear in the least 'rule-like', much to the chagrin of students fresh from studying criminal codes or contract law.

Common law areas also appear more 'rule-like' due to the way that doctrine is conceptualised and represented in legal thought. In the final analysis, a legal 'doctrine' in the common law is an extrapolation from what has been decided and said in a group of cases-it is a more abstract characterisation of the effect of those decisions, of the kind frequently presented in academic treatises. In representing the effect of a group of cases it is necessary to state their effect in a more context-independent manner, and to try to draw out from what is said the general effects of the decisions. ${ }^{36}$ But this abstract characterisation is more akin to a rough guide to the law than a set of binding rules. They have more of the character of rules of thumb than statutory rules, as anyone who has looked up the original texts of the cases confidently cited in support of some proposition of law in a treatise will have discovered. The cases are rarely quite as unequivocal in their support for the proposition of law for which they are cited, and frequently the cases provide only doubtful support for such propositions. Treatise writers attempt to impose some order on the decided cases-to rationally reconstruct what has been said and done in those cases. But the law turns on the detail of what was decided in the cases, not on how they might be consistently represented. ${ }^{37}$

Judges also cite doctrine, again as a useful shorthand way of summarising the state of the law in some area. Cases normally arise against a backdrop of existing doctrine, permitting counsel and court to characterise the facts in appropriate legal categories. A case is a dispute over the legal significance of what has occurred. Most appellate cases involve a dispute over some particular aspect of current doctrine, as the parties choose which aspects of the case to press before the court as the basis for obtaining the result they seek. So the parties may accept, as the basis for their argument, that the relevant legal doctrine can be summarised as follows:

36 This is accentuated where the discussion abstracts from a particular jurisdiction, and considers the 'law' of a country with separate jurisdictions (such as the contract law of the 'United States'), or where a 'model' doctrine roughly based on existing practice is proposed, as in the Restatements.

${ }^{37}$ Historically, some areas of the common law have also become more rule-like due to the authority of certain texts, such as Hale's Pleas of the Crown, being used in preference to the (relatively inaccessible) cases. 
Doctrine $=$ If $\{J, K, L, \sim M, \sim N\}$ then $C$

The case will normally focus on the proper understanding of only some part of the doctrine (e.g. what situations $J$ or $K$ or $L$ really cover), or whether the precedents supporting it can be distinguished. Only part of the doctrine will be in issue in any one case, and counsel and court will accept, for the sake of the dispute, that the case otherwise falls within the scope of the doctrine, meaning that these other aspects will not be scrutinised. So doctrine helps to frame the dispute. In reality, of course, there may be controversial questions about whether $\sim M$ really is required by the authorities, and what exactly $K$ involves. The 'statement' of the doctrine is useful, but the doctrine itself has lots of rough edges and loose ends which only emerge once one turns to the detail of what was said in the relevant authorities. But for the sake of this dispute, all of that is put to one side. If the court decides in case $\mathrm{P}_{12}$ that the presence of feature $U$ distinguishes the case, then the doctrine could be re-stated as:

Doctrine* $=$ If $\{J, K, L, \sim M, \sim N, \sim U\}$ then $C$

The ratio of $\mathrm{P}_{12}$, strictly speaking, is that $\sim U$ is necessary for the doctrine to apply. To reach the conclusion that $U$ distinguishes this case from the earlier precedents the court will have to do two things. It will have to reassure itself that $U$ really does present a novel situation that has not arisen already in the case-law. If it is satisfied on that score, it will have to reach a conclusion on the justification for the doctrine as a whole, i.e. provide a rationale for a doctrine with this shape. Only if it does so can it determine whether the presence of $U$ defeats the reason given by $\{J, K, L, \sim M$, $\sim N\}$ in support of $C$. Again, then, doctrine does not form a selfsufficient 'rule' which can be applied to the later case: it is a useful statement of the general effect of a group of authorities which provides the starting point for an analysis of the legal position. This provides a further explanation why later courts are not bound by the justifications given by a precedent court for its ratio. The justifications involve the consideration of questions broader than the issue under dispute, since the only question to be decided was what the court should do in the novel circumstances of $\left\{j_{12}, k_{12}, l_{12}\right.$, 
$\left.\sim m_{12}, \sim n_{12}, u_{12}\right\}$, not what the proper justification is for all of the previous cases.

Case-by-case decision-making, then, is not rule-based decisionmaking, though its operation over a long period can make its operation appear similar. Cases are context-dependent, and do not purport to settle what should be done in a different context. Instead they exercise an influence on later decisions because of the requirement that later courts treat the precedent as correctly decided. Once this perspective is taken on the doctrine of precedent, a range of features of the common law make much more sense than they otherwise would.

Most obviously, this approach integrates distinguishing into the common law, since it explains why the fundamental obligation of a later court is to either follow or distinguish, depending upon whether the differences between the two cases justify a different result. But to repeat a point touched on before, it also explains why common law courts, especially appellate courts, devote so much attention to a recitation of the facts of the case (unlike the practice in many civilian legal systems, such as the French). Without the facts one cannot properly understand what was decided, since one cannot know which distinctions are permissible and which are impermissible. If all the case was doing was laying down a general rule, such as a statutory rule, then the context of its creation would be relevant only to its interpretation. Instead, the context is crucial to its effect. Equally, the failure of common law courts to provide a canonical formulation as a basis for their rationes starts to make sense. It is not that the courts are somewhat slipshod in their approach, or that they are simply maintaining a particular tradition of judgment-writing. Purporting to state the ratio abstracted from the facts of the case would create the misleading impression that the decision was laying down a context-independent rule. Instead the ratio is only intelligible against the background facts of the case and the issue the parties have asked the court to resolve. The resolution of the case can only be justified by the court if it weaves together the particular facts, the issue, and its arguments over the resolution of the issue. Once that has been done, there is nothing left to be stated by the court, except to make the relevant orders appropriate to the disposal of the case. 


\section{The function of the doctrine of precedent}

What is the point of case-by-case decision-making? If precedents do not exist to create common law rules, what role do they serve? Some pointers to this may be gleaned from a consideration of the historical origins of the modern doctrine of binding precedent. The common law was originally thought of as the collective understanding of the legal profession. As this ancient view dissolved, the modern doctrine of precedent emerged. Historically the common law had existed without a strict doctrine of precedent. ${ }^{38}$ What seems to have made this possible was the size and the culture of the legal profession. Small, close-knit, of a certain social standing and social background, living and working in close proximity, the profession had a far more homogeneous outlook than its modern counterparts. Although there were uncertainties and disputes in this setting, there was also the assumption that these could only be settled by the emergence of a consensus on the correct result. The emphasis was on consensus, something still reflected in the common law's attachment to the unanimity of a jury's decision in preference to a verdict by simple majority. In this context a decision of a court was followed because it was correct. A mistaken decision was just that: a mistake. Decisions taken on their own did not make law: the law was the profession's present consensus over doctrine. ${ }^{39}$ Hence the thought that judicial decisions could only be, at best, evidence of the law, not the law itself.

The common law doctrine of binding precedent changes this by requiring later courts to treat earlier cases as correctly decided on their facts. It thereby serves two purposes: (a) fixing certain starting points for legal reasoning, while (b) not giving courts law-making

38 As has been emphasised by Simpson 1973 and Postema 2002. Simpson's suggestion $(1973,373-6)$ that the common law was a system of customary law, however, is open to criticism if it is taken to mean that the common law was based on convention: see Perry 1987, 253-4.

39 Prior to the Renaissance and the rise of printing the consensus seems to have been based on the profession's collective understanding of the law; later, it became the profession's collective understanding of the extant case law. See Baker 2003, $486-9$. 
power. This may sound puzzling: what is the point of fixing starting points for reasoning, and how can this be done without courts having law-making power? But it is actually not puzzling at all. The common law fixes starting points for legal reasoning because this is sufficient to make the law relatively predictable, and to compensate for the loss of commitment to consensus. On the other hand, court decisions can change the law without courts being given the power to change the law-because there is a crucial difference between one's actions having a normative effect and one's actions having that effect because one possesses the normative power to bring it about. ${ }^{40}$ To possess a normative power it must be the case that the reason one's actions bring about the normative effect is in order to enable one to bring that effect about by those actions. But in the circumstances described above it would be perverse to give the courts the power to alter the law. To give the courts law-making power in the face of the decline in the hold of consensus would be to exacerbate the very problem it is supposed to solve, not ameliorate it.

Looking first at the fixed starting points. A precedent creates a situation that provides incomplete guidance to later courts: it gives them a reason to reach a certain conclusion and rules out certain grounds for defeating that reason. From the point of view of legally binding guidance, later courts are relatively unconstrained in the result they could reach. But that is an extremely limited perspective to take on the law. Although later courts are very incompletely guided by the precedent and legal reasoning, their decisions are far more predictable than these resources could explain. To say this, of course, is to say nothing new: it is the crux, after all, of Llewellyn's critique of 'formalistic' approaches to legal reasoning. ${ }^{41}$ The courts' decisions are far more predictable than legal materials and canons of legal reasoning would seem to warrant: not because of some crude fact like the social background of the judiciary, but because of the way that law as a total institution provides much more than sources and methods of reasoning to those who join it. This is as true of precedents as it is of statutory rules: learning the law—-thinking 'like

40 This aspect of normative powers is highlighted by Raz 1990, 98-104.

41 E.g. Llewellyn 1960. 
a lawyer'-involves absorbing a whole cultural outlook which makes certain resolutions far more eligible than others.

But even if that were so, it might be objected, surely precedent confers a legal power on the courts to achieve these fixed starting points? On the contrary: the doctrine of precedent operates without giving the courts law-making power. What the doctrine does is this: it requires later courts to treat earlier decisions of certain courts as correctly decided. It does not give earlier courts the power to lay down legal rules, either for the case before it or for other cases to be decided in the future. Precedent does not give earlier decisions a certain status by endowing the court with a power in order for it to be able to alter the law-it simply gives those decisions a certain legal effect which stretches beyond the dispute before the court. The precedent court knows its decisions will have those further effects in the law, but the point of precedent is to facilitate convergence in decisions, not to make law. The point of the actions which create precedents (the court's decision) is not to enable the court to 'make law', but to settle a concrete dispute before the court-hence the court does have the power to decide the case before it. It is only when courts overrule decisions that they exercise a normative power: here the point of the power is to enable the courts to alter the law. But not so when they are deciding a case. To decide a case a court may have to overrule a precedent, en passant, and it possesses this power to serve the same goal as the doctrine of precedent otherwise serves - to limit the influence of any one court to change the law.

Why deny the courts law-making power? Not because they are courts, i.e. because their only 'proper' function is to settle disputes. It is quite possible to endow courts with law-making powers. One can ask an institution to choose the best rule for an abstract class of situations and then apply that rule to a concrete dispute (the one before the court). But to do this is to endow courts with a power which can further dissensus. If one is concerned about the breakdown in judicial consensus, it is likely to make the situation worse. The point of the common law doctrine is to avoid inconsistency, while limiting the legal effect of earlier decisions. There are three fundamental limitations on the effects of a precedent: (a) the case is only 'binding' within the scope of the ratio, and thus on issue(s) in dispute before the court; (b) the earlier court 
cannot foreclose the grounds for distinguishing; and (c) in determining whether to follow or distinguish, later courts are not bound by what the precedent court would have done. These features of precedent serve to limit the legal effect of individual decisions, including decisions of ultimate courts of appeal.

The upshot of these limitations is that the influence of an individual decision rests more on how persuasive later courts find its arguments than on its legal effect. What the doctrine of precedent is seeking to achieve, then, is a subtle counterpoise to the erosion of consensus. By not endowing individual courts with the power to make law, and limiting the legal effect of their decisions, the common law gives judges good reasons to make decisions which will be justifiable to their brethren. But more than that, precedent contributes to the checks and balances which operate vertically and horizontally on judges within the common law. Higher courts can overrule lower courts' decisions as well as allow appeals from them, but higher courts sit as benches and cannot hear every possible appeal. Lower courts are bound by the decisions of higher courts, but must decide to follow or distinguish these decisions as and when they deem it appropriate. What all this means is that the common law as a whole remains what it has always been, the product of the collective judgement of the courts. 


\section{REFERENCES}

Alexander, L, (1989) 'Constrained by Precedent', Southern California Law Review 63: 1-64 (1996), 'Precedent', in A Companion to the Philosopby of Law and Legal Theory, D. Patterson (ed.), Oxford

Baker, J.H. (2003), The Oxford History of the Laws of England, Volume VI, 1483-1558, Oxford

Bell, J. (2000), 'Sources of Law', in P. Birks (ed.) English Private Law, Oxford

Cross, R. and Harris, J.W. (1991), Precedent in English Law, 4th edition, Oxford

Dworkin, R.M. (1978), Taking Rights Seriously, revised edition, London

Eisenberg, M. (1988), The Nature of the Common Law, Cambridge, Mass

Goldstein, L. (1987), ed., Precedent in Law, Oxford

Levenbook, B. (2000), 'The Meaning of a Precedent', Legal Theory 6: $185-240$

Llewellyn, K.N. (1960), The Common Law Tradition, Boston

MacCormick, D. N. (1994 [1978]), Legal Reasoning and Legal Theory, $2^{\text {nd }}$ ed, Oxford

(1987), 'Why Cases Have Rationes and What These Are', in Goldstein (1987)

Moore, M. (1987), 'Precedent, Induction, and Ethical

Generalization', in Goldstein (1987)

Perry, S. (1987) 'Judicial Obligation, Precedent and the Common Law', Oxford Journal of Legal Studies 7: 215-257

Postema, G. (2002), 'Philosophy of the Common Law', in Coleman \& Shapiro (eds) Oxford Handbook of Jurisprudence and Philosophy of Law, Oxford

Raz, J. (1979), The Authority of Law, Oxford

(1989) 'Facing Up' Southern California Law Review 62: 11531235.

(1990), Practical Reason and Norms, 2nd ed, Princeton NJ 
Schauer, F. (1987), 'Precedent', Stanford Law Review 39: 571-605

(1989) 'Is the Common Law Law?', California Law Review 77: 455-471

(1991) Playing by the Rules: A Philosophical Examination of Rule-Based Decision-Making in Law and in Life, Oxford

Simmonds, N. (1984), The Decline of Juridical Reason, Manchester

Simpson, A.W.B. (1961), 'The Ratio Decidendi of a Case and Doctrine of Precedent', in A.G. Guest ed., Oxford Essays in Jurisprudence, Oxford

(1973) [1987], 'The Common Law and Legal

Theory', reprinted in his Legal Theory and Legal History: Essays on the Common Law, Oxford 